\title{
What is the performance in vertebral fracture discrimination by BMD, TBS and FRAX in stand-alone, combined or adjusted approaches: The OsteoLaus Study
}

\author{
O Lamy, M.A Krieg, D. Stoll, B. Aubry-Rozier, M. Metzger, D. Hans \\ Center for Bone Diseases, Lausanne University Hospital, Switzerland
}

\section{Introduction}

Osteoporosis (OP) is a systemic skeletal disease characterized by a low bone mineral density (BMD) and a micro-architectural (MA) deterioration. Clinical risk factors (CRF) are often used as an indirect surrogate marker of MA (e.g. FRAX model). MA is yet more directly evaluable in daily practice by the Trabecular Bone Score (TBS) measure. TBS is a novel grey-level texture measurement reflecting bone micro-architecture based on the use of experimental variograms of $2 \mathrm{D}$ projection images. TBS has proven to have diagnosis and prognosis value, partially independent of CRF and BMD. Leslie B et al * proposed recently an adjustment of FRAX probability according to lumbar spine Trabecular Bone Score (TBS). The aim of the study is to compare the performance of FRAX versus TBS adjusted FRAX using their method to better identify women at high fracture risk.

\section{Methods}

OsteoLaus is a sub-study of Colaus which started five years later. OsteoLaus was proposed to all women $50-80$ years old who participated at the second Colaus visit between September 2009 and September 2012. At this time, near 85\% of the women (seen at the second visit in Colaus, with five years follow-up) accepted to participate in the OsteoLaus Study. We expected to include 1400 women. Clinical risk factors (CRF) for osteoporosis, FRAX, lumbar spine and hip BMD, VFA by DXA and MA evaluation by TBS are recorded in OsteoLaus. Preliminary results are reported. Sensitivity and specificity in regard to vertebral fracture grade $2 \& 3$ has been calculated for all bone modalities as stand-alone or combined approaches. The adjustment of FRAX by TBS has been applied as proposed by Leslie WD et $\mathrm{al}^{*}$. Integrated discrimination index and net reclassification improvement have also been investigated.

\section{Results}

We included 911 women: mean age $65.2 \pm 7.9$ y, BMI 25.7 \pm 4.4 , mean lumbar spine BMD 0.931 \pm 0.163 (T-score -1.04 SD), TBS $1.289 \pm 0.100$. As expected, correlation between BMD and site matched TBS is low ( $r 2=0.16)$. Prevalence of VFx grade $2 / 3$ and MOF are $7.5 \%$ and $15.0 \%$ respectively
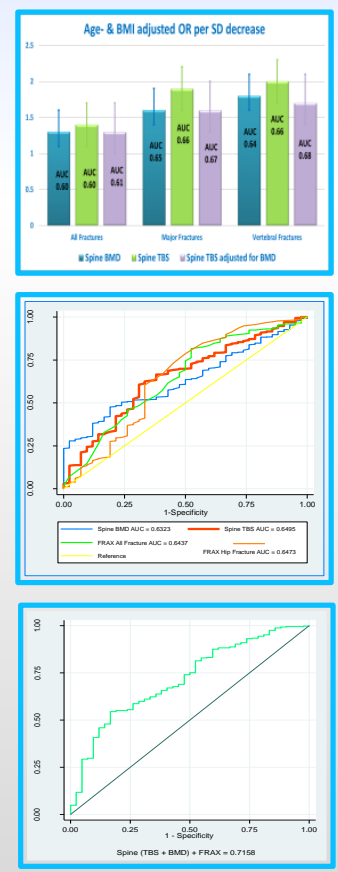

\begin{tabular}{|c|c|c|c|}
\hline \multicolumn{4}{|c|}{$\begin{array}{l}\text { Proposed adjustment to FRAX probability based upon } \\
\text { spine TBS tertile. }\end{array}$} \\
\hline & $\begin{array}{c}\text { Change to Major } \\
\text { osteoporotic fracture } \\
\text { probability }\end{array}$ & \multicolumn{2}{|c|}{$\begin{array}{l}\text { Change to Hip } \\
\text { fracture probability }\end{array}$} \\
\hline $\begin{array}{l}\text { For TBS in the lowest tertile: } \\
\text { For TBS is in the middle tertile: } \\
\text { For TBS is in the highest tertile: }\end{array}$ & $\begin{array}{c}+25 \% \\
\text { no change }\end{array}$ & & $\begin{array}{l}\text { no change } \\
\text { no change }\end{array}$ \\
\hline & & Sensitivity & Specificity \\
\hline Spine BMD (-2.5 T-score threshold) & & $29.4 \%$ & $82.7 \%$ \\
\hline Lowest BMD (-2.5 T-score threshold) & & $35.3 \%$ & $80.9 \%$ \\
\hline Spine TBS (-1.200 threshold) & & $51.5 \%$ & $77.1 \%$ \\
\hline FRAX MOF (20\% threshold) & & $38.2 \%$ & $94.8 \%$ \\
\hline Lowest BMD or TBS thresholds & & $64.7 \%$ & $65.4 \%$ \\
\hline Spine TBS or FRAX MOF (20\%thresho & Ids) & $63.2 \%$ & $74.4 \%$ \\
\hline TBS adjusted FRAX All fracture ( $20 \%$ & threshold) & $50.0 \%$ & $89.9 \%$ \\
\hline
\end{tabular}

When used to reclassify fracture risk, this gave a significant increase in integrated discrimination index for VFx $(+2.5 \%, \quad \mathrm{P}<0.001)$, with net reclassification improvement $+7.6 \%$ for VFx $(P<0.001)$.
* WD. Leslie et al.. Lumbar Spine TBS is a FRAX Independent Risk Factor for Fracture: The Manitoba BMD Cohort. ISCD Annual meeting 2013. Tampa. Florida.

\section{Conclusion}

While the optimal threshold for TBS should be investigated, an incremental improvement in fracture identification was seen by using lumbar spine TBS in combination with FRAX. If validated in prospective cohorts, lumbar spine TBS may become clinically useful for enhancing fracture prediction from FRAX. Such simple way to take TBS into account would allow the use of current medical recommendations regarding osteoporosis management with only minor adaptations. 